\title{
Ventricular fibrillation caused by electrocoagulation in monopolar mode during laparoscopic subphrenic mass resection
}

\author{
Chun-Yan Yan · Xiu-Jun Cai · Yi-Fan Wang • \\ Hong Yu
}

Received: 13 December 2009/ Accepted: 3 May 2010/Published online: 30 June 2010

(C) The Author(s) 2010. This article is published with open access at Springerlink.com

\begin{abstract}
Background Monopolar is usually a safe and effective electrosurgical unit used in laparoscopic general surgery. However, it can cause adverse outcomes and even cardiac arrest. We present a video of laparoscopic subphrenic mass resection using monopolar coagulation during which ventricular fibrillation occurred and from which the patient was successfully resuscitated.

Methods Our patient was a 39-year-old man who was admitted to our institution for treatment of a liver mass. The mass was located in the left subphrenic region and was $3.31 \mathrm{~cm} \times 2.7 \mathrm{~cm}$ according to B ultrasound. He had had a spleen resection after a car accident 14 years before. He was otherwise healthy and a physical examination was negative. He was scheduled for "laparoscopic exploration, mass resection." General anesthesia was induced and the operation began. While dissecting the mass from the diaphragm there was some bleeding; monopolar electrocoagulation with $68 \mathrm{~W}$ was performed upon which ventricular fibrillation occurred. The operation was stopped and
\end{abstract}

Electronic supplementary material The online version of this article (doi:10.1007/s00464-010-1157-0) contains supplementary material, which is available to authorized users.

X.-J. Cai $(\bowtie) \cdot$ Y.-F. Wang · H. Yu

Department of General Surgery, Institute of Minimally Invasive Surgery, Sir Run Run Shaw Hospital, Zhejiang University

School of Medicine, No. 3, Qingchun Road East,

Hangzhou 310016, China

e-mail: caixiujunzju@yahoo.com.cn

C.-Y. Yan

Department of Anesthesiology, Sir Run Run Shaw Hospital, Zhejiang University School of Medicine, No. 3, Qingchun Road East, Hangzhou 310016, China closed-chest compression began immediately. Defibrillation (200-J shock) was performed in $1 \mathrm{~min}$ and rhythm returned to sinus.

Results The operation was resumed carefully and uneventfully. The patient was sent to the postoperative acute care unit and was extubated 10 min after operation. The patient recovered uneventfully without any signs of permanent cardiac injury and was discharged on postoperative day 3 . The final pathology was accessory spleen.

Conclusions We present a video of a patient who experienced ventricular fibrillation during laparoscopic surgery which was successfully defibrillated leaving no permanent cardiac injury. We assume the reason for the ventricular fibrillation was the low-frequency leakage current from electrocoagulation which may be conducted by Swan-Ganz catheter to the heart. It is important that we be familiar with the character of electrosurgical unit when performing laparoscopic surgery. We should be careful when using an electrosurgical unit near the cardiac region, especially when the patient has an indwelling catheter. We recommend performing hemostasis in bipolar mode or use an ultrasonic scalpel if bleeding is close to the heart. Also, an easily available defibrillator should be ready for use.

Keywords Laparoscopic surgery · Ventricular fibrillation · Electrocautery · Monopolar mode

Electrocautery is one of the most commonly used instruments in the laparoscopic surgery. Monopolar is the most popular mode used in general surgery. It is safe and effective most of the time if applied appropriately. However, it can cause adverse outcomes and even cardiac arrest. We present a video of laparoscopic subphrenic mass resection using monopolar coagulation during which 
ventricular fibrillation occurred and the patient was successfully resuscitated.

\section{Patient and treatment}

A 39-year-old man was admitted to our hospital for treatment of a liver mass. The mass was located in left subphrenic region and was $3.31 \mathrm{~cm} \times 2.7 \mathrm{~cm}$. He had had a spleen resection after a car accident 14 years before. He was otherwise healthy and a physical examination was negative. He was scheduled for "laparoscopic exploration, mass resection." A preoperative 12-lead electrocardiograph (ECG) was normal. Monitoring included an ECG (lead II, V 5), pulse oximeter, capnograph, and invasive arterial blood pressure (ABP) monitor (Datex-Ohmeda $\mathrm{S} / 5$, Helsinki, Finland). A Swan-Ganz catheter (7Fr, Arrow International Inc., Reading, PA, USA) was implanted before surgery and pulmonary arterial pressure was monitored during surgery.

Induction of anesthesia and intubation with a No. 7.5 endotracheal tube were uneventful. Anesthesia was maintained with continuous intravenous infusion of isoflurane, propofol, and remifentanil via pump.

As seen in the video, the mass was located in the apex of diaphragm, near the left coronary ligament, and had a smooth edge. While dissecting the mass from the diaphragm, one can see clearly from the video that the vessels of the diaphragm were bleeding and that controlling them by clip would be difficult. Monopolar electrocoagulation (Valleylab Force 2 electrosurgical unit, Valleylab, Boulder, CO, USA) with $68 \mathrm{~W}$ was thus performed upon which ventricular fibrillation occurred. The operation was stopped immediately, the laparoscopic instruments and trocars were pulled out, and closed-chest compression was begun. The mean ABP was maintained at $60-70 \mathrm{mmHg}$. One minute later defibrillation (200-J shock) was performed, and rhythm returned to the sinus. Arterial blood gas was determined and showed $\mathrm{pH} 7.35$ and $\mathrm{K}+2.8 \mathrm{mmol} / \mathrm{L} ; 1 \mathrm{~g}$ $\mathrm{KCl}$ was administered via pump.

\section{Results}

The operation was resumed carefully and uneventfully. The patient was sent to the postoperative acute care unit (PACU) after surgery. He was extubated 10 min after surgery. Arterial blood gas was done again $2 \mathrm{~h}$ after the operation and showed $\mathrm{pH} 7.38$ and $\mathrm{K}+3.9 \mathrm{mmol} / \mathrm{L}$. The levels of troponin I, CK, CKMB, and $\mathrm{LDH}$ were $0.41 \mathrm{ng} / \mathrm{ml}, 712 \mathrm{IU} / \mathrm{L}, 13 \mathrm{IU} / \mathrm{L}$, and $311 \mathrm{IU} / \mathrm{L}$, respectively (normal levels are $<0.1 \mathrm{ng} / \mathrm{ml}, 39-275 \mathrm{IU} / \mathrm{L}, 0-16 \mathrm{IU} / \mathrm{L}$, and 60-213 IU/L, respectively). These parameters were tested again the following day and the results were $0.21 \mathrm{ng} / \mathrm{ml}, 748 \mathrm{IU} / \mathrm{L}, 18 \mathrm{IU} / \mathrm{L}$, and $376 \mathrm{IU} / \mathrm{L}$, respectively. The patient recovered uneventfully and was discharged on postoperative day 3 .

\section{Discussion}

The reasons that ventricular fibrillation (VF) occurred could be patient- or material-related. Because the patient was healthy before surgery and recovered soon afterward, without any signs of permanent cardiac injury, a possible explanation for VF could be unwanted electrical injury that may have been caused by a low-frequency leakage current. In monopolar mode, high-frequency $(510 \mathrm{kHz}$ in this case) currents flow from the generator through the active electrode, into target tissue, through the patient, the dispersive electrode, and return to the generator. The desired electrosurgical effect happens only at the active electrode. However, monopolar mode can cause potential problems such as low-frequency $(50-60 \mathrm{~Hz})$ "stray current." The most sensitive frequency for myocardium is $30-110 \mathrm{~Hz}$, so this lowfrequency leakage is ideal for inducing fibrillation [1].

If electrical contact is made on or close to the heart, a current as low as $10 \mathrm{~mA}$ may cause dysrhythmia [1]. In our case, the mass was located on top of the diaphragm, which is very close to the heart. Electrocoagulation was $68 \mathrm{~W}$ so the current was far more than $10 \mathrm{~mA}$. This may be one reason VF was induced.

Another cause of VF could be capacitive coupling leading to a low-frequency current. The risk was increased when using coagulation mode [2]. Low-frequency leakage is much more common when the patient has a cardiac catheter, a pulmonary artery catheter, or a central venous pressure (CVP) catheter [3]. The intracardiac catheter may produce a low-resistance path to ground through the patient's heart and thereby place the patient at risk for electrically induced ventricular tachycardia (VT) or VF. The role of the intracardiac catheter as a vector of leakage current is supported by experimental study and clinical observations [4]. In our case, an arc may be produced between the diaphragm and the tip of the electrode when dissecting and controlling bleeding by the coagulation mode. Also, the inserted pulmonary artery catheter and conductive saline used as fluid in the catheter may increase the risk of inducing VF.

\section{Conclusion}

While using an electrosurgical unit to prevent VF (leaking current) the following should be kept in mind: 
1. As the VF threshold decreases when the duration of the $\mathrm{AC}$ current increases, if leakage current lasts $5 \mathrm{~s}$ or longer, the patient with intracardiac electrodes may suffer from VT or VF when the leakage AC current is less than $50 \mu \mathrm{A}$ [5]. We should avoid using the coagulation mode to cut, especially near the cardiac region, in laparoscopic surgery for more than $5 \mathrm{~s}$.

2. Because the flow of current is restricted between two poles and low voltages are used to achieve the effect in bipolar mode, it is more suitable to perform hemostasis in bipolar mode than in monopolar mode when bleeding is close to the heart. An ultrasonic scalpel also should be considered because no electrical current and little heat are produced during coagulation.

3. One should be more careful using an electrosurgical unit in a patient who has an intracardiac catheter.

4. Once VF has occurred, the patient's survival depends on rapid interruption of the leakage-current circuit and cardioversion equipment should be ready immediately to defibrillate.

In conclusion, we present a video of a patient who during laparoscopic surgery experienced ventricular fibrillation which was successfully defibrillated, leaving no permanent cardiac injury. We assume the reason was the low-frequency leakage current which perhaps was conducted by the Swan-Ganz catheter to the heart. It is important that we be familiar with the character of the electrosurgical unit when performing laparoscopic surgery. We should be careful when using an electrosurgical unit near the cardiac region, especially when the patient has an indwelling catheter. Using an ultrasonic scalpel should be considered while operating in this area. Also, an easily available defibrillator should be ready for use.

Disclosures Drs. Yan, Cai, Wang, and Yu have no conflicts of interest or financial ties to disclose.

Open Access This article is distributed under the terms of the Creative Commons Attribution Noncommercial License which permits any noncommercial use, distribution, and reproduction in any medium, provided the original author(s) and source are credited.

\section{References}

1. Dalibon N, Pelle-Lancien E, Puyo P, Leclerc JF, Fischler M (2005) Recurrent asystole during electrocauterization: an uncommon hazard in common situations. Eur J Anaesthesiol 22:476-478

2. Voyles CR, Tucker RD (1992) Education and engineering solutions for potential problems with laparoscopic monopolar electrosurgery. Am J Surg 164:57-62

3. Mitsuhata H, Ohtaka K, Matsumoto S, Hasegawa J (1991) Ventricular arrhythmia associated with the use of an electrosurgical unit in a patient with a Swan-Ganz catheter. Masui 40:986990 [in Japanese]

4. Monies-Chass I, Vilensky A, Mordechowitz B, Birkhahn J (1986) Hidden risk in operating room. Micro-shock. Acta Anaesthesiol Belg 37:39-44

5. Swerdlow CD, Olson WH, O'Connor ME, Gallik DM, Malkin RA, Laks M (1999) Cardiovascular collapse caused by electrocardiographically silent $60-\mathrm{Hz}$ intracardiac leakage current. Implications for electrical safety. Circulation 99:2559-2564 